\title{
Comparison of Operating Time between Stand-alone Cage and a Standard Method for a Single Level Cervical Disc Disease
}

\author{
Chang Hyoun Kim, Chi Heon Kim, Chun Kee Chung, Tae-Ahn Jahng \\ Department of Neurosurgery, Seoul National University College of Medicine; Neuroscience Research Institute, Seoul National \\ University Medical Research Center; Clinical Research Institute, Seoul National University Hospital, Seoul, Korea
}

Objective: Autologous bone graft with anterior plating had been a standard method for anterior cervical discectomy and fusion (ACDF). Drawbacks of a standard method were donor site problem and problem associated with anterior plate. The stand-alone cage was introduced to reduce such problems. However, problems associated with subsidence and local kyphosis at the index level (segmental kyphosis) still persist with stand-alone cage and a standard method would be required in some cases. It seems that harvest of autologous bone and anterior plating procedure is time consuming, but this has not been verified. The aim of this study was to compare the operating time between patients operated on with standalone cage versus a standard method for single-level cervical disc disease.

Methods: Consecutive 29 patients (M:F=18:11; mean age, 58.4 \pm 12.4 years), who had undergone ACDF for single-level disc disease by a single surgeon from incision to closure during 2009-2011, were selected for this retrospective study. Seventeen patients were operated with stand-alone cage (Group I), and twelve patients were with a standard method (Group II). Operating time (from incision to closure), estimated blood loss, clinical and radiological outcomes were compared. Follow-up period was $11.4 \pm 6.3$ months.

Results: Operating time was not different between groups longer; Group I (96.1 \pm 28.7 minutes) and Group II (112.4 \pm 31.7 minutes) $(p=0.13)$. There was no surgery related complication. Excellent or good outcome was achieved in 11 and 10 patients of group I and II, respectively. Bony fusion was achieved in 15 and 10 patients of group I and II respectively, while one subsidence occurred in each group. Postoperative segmental angle at the index level and cervical curvature was not different between groups. No patient complained donor site pain at the last follow-up.

Conclusions: ACDF with a standard method for single-level cervical disc disease was not a time-consuming procedure comparing stand-alone cage.

Key Words: Cage $\cdot$ Plate $\cdot$ Cervical $\cdot$ Spine $\cdot$ Discectomy $\cdot$ Standard

\section{INTRODUCTION}

Anterior cervical discectomy and fusion (ACDF) has been the standard treatment method for a cervical disc disease ${ }^{5)}$.

- Received: February 1, 2012 - Revised: March 10, 2012

- Accepted: March 28, 2012

Corresponding Author: Chi Heon Kim, MD, PhD

Department of Neurosurgery Seoul National University College of Medicine,

28 Yeongeon-dong, Jongno-gu Seoul 110-744, Korea

Tel: +82-2-2072-3398, Fax: +82-2-744-8459

E-mail: chiheon@hanmail.net

Acknowledgement: This work was supported by the National Research Foundation of Korea(NRF) grant funded by the Korea government (MEST) (2011-0000378)

Disclaimer: The authors report no conflict of interest concerning the materials or methods used in this study or the findings specified in this paper. The Institutional Review Board of the Clinical Research Institute at Seoul National University Hospital (D-0804-044-004) approved this study.
However, there are several problems associated with bone graft and instrument; subsidence, collapse of graft and mechanical failure. Such drawbacks have been discussed in many literatures ${ }^{2,22,23)}$. Recently, the stand-alone cage is used mostly due to its technical simplicity and comparable fusion rate to that of autologous iliac bone grafting with or without anterior plating ${ }^{7,30,31)}$. Moreover, there is no need to spend time in harvesting autologous bone and applying anterior plate. However, problems associated with subsidence and local kyphosis at the index level (segmental kyphosis) still persist with standalone cage and a standard method would be beneficial in some cases $^{1,2,8-11,13,14,20,26,29)}$. It seems that harvest of autologous bone and anterior plating procedure are time consuming ones, but such comparison has not been performed. The aim of this retrospective study was to compare the operating time between patients who underwent ACDF with stand-alone cage and with a standard method. 


\section{MATERIAL AND METHODS}

\section{Patient}

From June 2009 to April 2011, patients who had ACDF for treatment of single-level cervical disc disease causing radiculopathy or myelopathy were included in the study. These patients were included in clinical trial (www.clinicaltrials.gov, NCT01011569) to compare clinical and radiological efficacy of stand-alone cage versus anterior plating with autologous iliac bone graft for single-level cervical disc disease. Two surgeons participated in the clinical trial and a random number table assigned the method of fusion (stand-alone cage or anterior plating with autologous iliac bone graft). Patients with radiculopathy or myelopathy due to disc herniation, osteophyte formation, or hypertrophied posterior longitudinal ligament were recruited for this study. Patients who had surgery in neck area, radiotherapy, severe myelopathy (Nurick grade poorer than ${ }^{3,17)}$, severe osteoporosis $(\mathrm{T}<-3.0)^{24)}$, risk factors for osteoporosis (e.g., history of long-term steroid usage or renal failure), ossified posterior longitudinal ligament in any cervical spine level, previous history of surgery for the cervical spine, or systemic infection or malignancy were excluded from the clinical trial. The surgeon was informed on the day of the operation as to what fusion method was to be used by the physician assistant (registered nurse), who did not participate in the operation and analysis of data. Finally, Twenty-nine patients, performed ACDF by a single surgeon $(\mathrm{KCH})$ from incision to closure, were selected in this retrospective study. Seventeen patients (M:F=9:8; age, 55.7 \pm 11.8 years; ranges 35-85) had operated on with stand-alone cage (Group I) and twelve patients (M:F=9:3; age, 62.2 \pm 12.6 years; ranges 4877) had with anterior plating with autologous iliac bone graft
(Group II). The operated levels were C3-4 in 4 patients, C4-5 in 5, C5-6 in 5 and C6-7 in 3 patients in Group I and C3-4 in 3, C4-5 in 2, C5-6 in 4 and C6-7 in 3 in Group II. Unfortunately, neck thickness, which may be correlated with neck thickness and prolong operative time, was not measured. Instead, body mass index (BMI) was calculated to estimate neck obesity. Preoperative work-ups included plain X-rays (standing anterior-posterior, lateral neutral, lateral flexion, and lateral extension view), computed tomography (CT), and magnetic resonance (MR) imaging. After the operation, the patients were scheduled to visit an outpatient clinic at $1,3,6$, and 12 months and yearly thereafter. The patients had plain Xrays taken (standing anterior-posterior, lateral neutral view, lateral flexion, and lateral extension view) at every visit. The average follow-up period was 10.6 \pm 6.3 months and $11.3 \pm 5.9$ months in group I and II, respectively. Characteristics of groups were described in Table 1.

\section{Clinical and radiological follow-up}

Clinical outcome was assessed by Odom's criteria (excellent, good, fair and poor) ${ }^{32)}$. Operative time, estimated blood loss, cervical curvature (CA), segmental angle at the operated level (SA), fusion rate and subsidence rate was compared between groups.

The anesthetic record was reviewed to calculate operative time from incision to closure and estimated blood loss. As mentioned, all operative procedures were performed by a single surgeon from incision to closure including iliac bone harvest. Estimated blood loss was assessed by anesthesiologist's recording. The angle of the cervical curvature (CA) between $\mathrm{C} 2$ and $\mathrm{C} 7$ was measured in the plain X-ray by using tangential method ${ }^{2,14)}$. The segmental angle at the index level (SA) was measured in the plain X-ray by using Cobb's method between the superior endplate of the cephalic and inferior end-

Table 1. Characteristics of groups

\begin{tabular}{|c|c|c|c|c|c|}
\hline \multicolumn{2}{|l|}{ 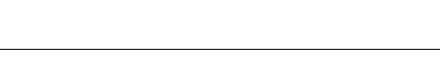 } & Group I & Group II & p-value & Total \\
\hline \multicolumn{2}{|l|}{ Age } & $55.7 \pm 11.8$ & $62.2 \pm 12.6$ & 0.08 & $58.4 \pm 12.4$ \\
\hline \multicolumn{2}{|l|}{$\operatorname{Sex}(M: F)$} & $9: 8$ & $9: 3$ & 0.28 & 18:11 \\
\hline \multirow[t]{4}{*}{ Surgery levels } & C3-4 & 4 & 3 & & 7 \\
\hline & $C 4-5$ & 5 & 2 & & 7 \\
\hline & C5-6 & 5 & 4 & & 9 \\
\hline & C6-7 & 3 & 3 & & 6 \\
\hline \multicolumn{2}{|l|}{ Height (m) } & $1.6 \pm 0.1$ & $1.6 \pm 0.1$ & 0.58 & $1.6 \pm 0.1$ \\
\hline \multicolumn{2}{|l|}{ Weight (kg) } & $65.0 \pm 9.2$ & $63.4 \pm 12.5$ & 0.57 & $64.3 \pm 10.5$ \\
\hline \multicolumn{2}{|c|}{ Body mass index $\left(\mathrm{kg} / \mathrm{m}^{2}\right)$} & $24.6 \pm 3.3$ & $24.2 \pm 2.7$ & 0.97 & $24.5 \pm 3.0$ \\
\hline \multicolumn{2}{|l|}{ Followup } & $10.6 \pm 6.3$ & $11.3 \pm 5.9$ & 0.42 & $10.9 \pm 6.0$ \\
\hline
\end{tabular}


plate of the caudal vertebra of the operated segment ${ }^{13,14)}$. Subsidence was defined as a decrease of the vertical anterior or posterior height by more than $3 \mathrm{~mm}^{1,12,25,27,30)}$. The operated segment was deemed to be fused if there was less than $2^{\circ}$ of motion at the operated segment on a dynamic view ${ }^{6}$. Additionally, the radiological images of group I were evaluatedusing the classification of anterior fusion proposed by Vavruch et $\mathrm{al}^{28)}$. In this classification; Type $1 \mathrm{~A}$ is defined as bridging bone anterior and through the disc space; $1 \mathrm{~B}$ as bridging bone anterior but not through the disc space; $2 \mathrm{~A}$ as bridging bone not anterior but through the disc space; and $2 \mathrm{~B}$ as no bridging bone at all. The radiological outcomes were classified as 'nonfusion' if $2 \mathrm{~B}$ healing was observed and as 'fusion' if $1 \mathrm{~A}, 1 \mathrm{~B}$, or $2 \mathrm{~A}$ healing was observed at the levels subjected to the surgery ${ }^{6,28}$. Bony fusion of group II was defined as 'fused with remo deling and trabeculae present ${ }^{18)}$ or 'graft intact, not fully remodeled and incorporated, but no lucency present', according to the Bridwell criteria (criteria I or II). ${ }^{3)}$ If lucency or collapse/ resorption of the graft was present, this was regarded as indication no fusion (criteria III or IV) ${ }^{3)}$. The institutional review board at our hospital approved this study (D-0804-044-004).

\section{Operative techniques}

A standard anterior-medial approach was used in all 29 cases. After applying Caspar screws at the index level, the screws were distracted to determine the height of the graft/cage. Fluoroscopic image was taken to confirm operated level. Then the anterior longitudinal ligament (ALL) and annulus were cut and the disc was removed with pituitary forceps and curette. The endplate was carefully prepared with curettes. Pneumatic drill and Kerrison punch were used to remove posterior spur. The posterior longitudinal ligament was removed in all cases and decompression of the spinal cord and nerve root was confirmed. For fusion with stand-alone cage, the size of the cage $\left(\mathrm{MC}+{ }^{\circledR}\right.$, LDR Medical, France or Solis ${ }^{\circledR}$, Stryker, USA) was determined after inserting a trial cage. The cage was filled with allomaterial (a Type 1 collagen/hydroxyapatite matrix; Healos ${ }^{\circledR}$, Depuy Spine, USA) soaked with autologous bone marrow aspirated from the iliac crest. An adequate-sized implant was inserted into the disc space with gentle tapping. For fusion with anterior plating and autologous bone graft, tri-cortical autologous iliac bones was harvested from left or right anterior superior iliac spine with a $1.5 \mathrm{~cm}$ incision of the skin, using an oscillating saw. The harvested autologous iliac bone graft was inserted with gentle tapping. A semi-constrained type of anterior plate (Atlantis ${ }^{\circledR}$, Medtronic Sofamor Danek, USA) was applied with variable angled screws. After finishing the instrumentation, the wound was closed in a layer-by-layer fashion after inserting a closed drain.

\section{Statistical analysis}

Mann-Whitney's U test was used for comparison of continuous and non-parametric values, and Chi-square test and Fisher's exact test were used for categorical data or values respectively. All statistical analyses were done using SPSS (version 17.0, SPSS, Chicago, IL, USA), and statistical significance was defined as $\mathrm{p}<0.05$.

\section{RESULT}

There were no differences in sex distribution ( $\mathrm{p}=0.28$, Fisher's exact test) and age ( $\mathrm{p}=0.08$; Mann-Whitney's U test). The BMI of group I was $24.6 \pm 3.3 \mathrm{~kg} / \mathrm{m}^{2}$ and the BMI in group II was $24.2 \pm 2.7 \mathrm{~kg} / \mathrm{m}^{2}$ ( $\mathrm{p}=0.97$; Mann-Whitney's U test, Table 1). In terms of surgical complication, there was no case of instrumentation associated problem during the operation and there was no case of malposition of instrument (cage, plate and screws), surgical infection, and mechanical failure, such as cage migration or screw pull-out/breakage during the follow-up period. Operation took 96.1 \pm 28.7 minutes (range, 55-165) in Group I and 112.4 \pm 31.7 minutes (range, 65-170) in Group II. The operation time was not statistically different between groups ( $\mathrm{p}=0.13$, Mann-Whitney's U test) (Table 2 and Fig. 1). EBL was $65.0 \pm 65.1 \mathrm{ml}$ (range, 10-200) in Group I and 80.0 065.6 $\mathrm{ml}$ (range, 10-200) in Group II without statistical difference ( $p=0.45$, Mann-Whitney's U test) (Table 2, Fig. 2).

Clinical and radiological outcome were assessed for patients followed up more than 3 months and oen patient was excluded in each group. By Odom's criteria, excellent or good outcome was achieved in 11/16 and 7/11 patients of group I and

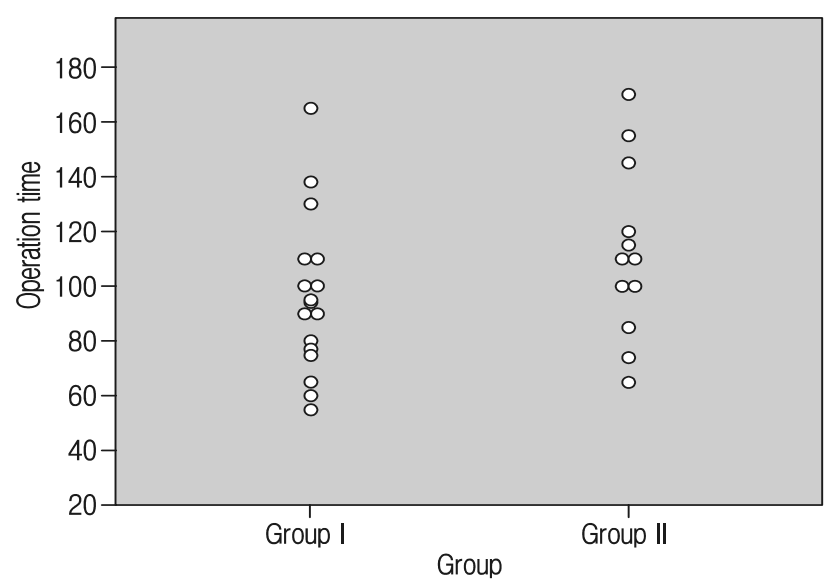

Fig. 1. Distribution of operation time between groups. Operation

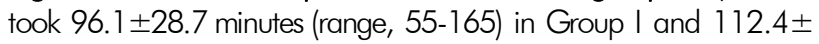
31.7 minutes (range, 65-170) in Group II. The operation time was not statistically different between groups ( $p=0.13$, Mann-Whitney's U test). 
Table 2. Clinical and radiological outcome

\begin{tabular}{|c|c|c|c|c|c|}
\hline & & Group I & Group II & p-value & Total \\
\hline Surgery time (min & & $96.1 \pm 28.7$ & $112.4 \pm 31.7$ & 0.13 & $102.9 \pm 30.5$ \\
\hline $\mathrm{EBL}(\mathrm{ml})$ & & $65.0 \pm 65.1$ & $80.0 \pm 65.6$ & 0.45 & $71.2 \pm 64.6$ \\
\hline \multirow[t]{4}{*}{ Odom's criteria } & Excellent & 8 & 5 & & 13 \\
\hline & Good & 3 & 2 & & 5 \\
\hline & Fair & 5 & 4 & & 9 \\
\hline & $\mathrm{N} / \mathrm{A}$ & 1 & 1 & & 2 \\
\hline Preop CA $\left(^{\circ}\right)$ & & $12.7 \pm 7.2$ & $8.7 \pm 11.9$ & 0.37 & $11.4 \pm 9.7$ \\
\hline postop CA & & $15.6 \pm 6.5$ & $10.2 \pm 12.8$ & 0.07 & $15.1 \pm 11.1$ \\
\hline Preop SA & & $1.4 \pm 4.8$ & $1.5 \pm 6.9$ & 0.84 & $1.5 \pm 5.7$ \\
\hline postop SA & & $3.3 \pm 3.4$ & $4.4 \pm 4.0$ & 0.92 & $3.8 \pm 4.7$ \\
\hline Fusion & & 15 & 10 & & 25 \\
\hline Subsidence & & 1 & 1 & & \\
\hline
\end{tabular}

Abbreviations: $C A$, cervical angle; $E B L$, estimated blood loss; SA, segmental angle; N/A, not available

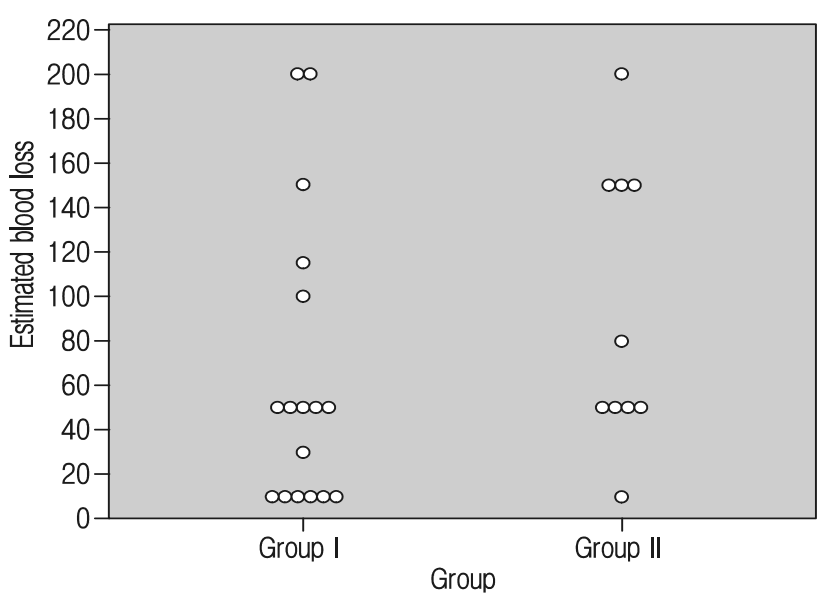

Fig. 2. Distribution of estimated blood loss between groups. Estimated blood loss was $65 \pm 65 \mathrm{ml}$ (range, 10-200) in Group I and $80 \pm 66 \mathrm{ml}$ (range, 10-200) in Group II. The amount of blee ding was not different between groups ( $p=0.45$, Mann-Whitney's $U$ test).

II, respectively without statistical difference between groups $(p=1.00$, Fisher's exact test, Table 2). No patient complained donor site pain at the last follow-up. Preoperative and postoperative CA and SA were not different between groups ( $\mathrm{p}$ $>0.05$, Table 2). Solid bony fusion was observed in $15 / 16$ and 10/11 patients of group I and II, respectively (Table 2). Subsidence was occurred in a patient in each group (Table 2).

\section{DISCUSSION}

Recent studies showed that clinical results were similar in comparative studies between the stand-alone cage and anterior plating 9,12,20,22,30,31). However, radiological outcome was not similar and a number of studies have pointed out the occurrence of subsidence and kyphosis after the use of a stand-alone cage in up to $45 \%$ of patients, although those were not correlated with poor clinical outcomes during their follow-up periods $4,6,7,12,15,16,19,30,31)$. Taking those results together, probably, there may be some patients who need a standard surgical method. Actually, harvesting iliac bone and supplemental anterior plating may not be preferred method for some surgeons, due to donor site complication and mechanical problem associated with plating ${ }^{2,22,23)}$. In addition, it seems to be time-consuming and bleeding procedure. However, this has not been verified yet. In this regard, we performed retrospective study to compare surgical time of two different ACDF methods for single-level cervical disc disease; stand-alone cage vs. a standard method; autologous iliac bone graft with anterior plating.

In the present study, the clinical outcome and radiological outcome, which was assessed by Odom's criteria, cervical curvature, segmental angle, fusion rate and subsidence rate, were not different between groups. However, this result, obtained in a small group, harbors a great chance of bias.

For the surgical time, it may be meaningful because the operation method was randomized and all surgeries were performed by a single surgeon from incision to closure. The BMI was not different from patients. Those fulfilled similarity of difficulty in operative procedures between two groups. The mean operation time was longer in group II than group I without statistical difference. Although, there was no statistical difference, it seemed that 16 minutes was used for anterior plating and bone harvesting. Additional bleeding was $15 \mathrm{ml}$ and it did not cause statistical difference. However, we should admit that measuring EBL by anesthetic record would be error-prone due 
to unmeasured insensible loss. At least, it seemed that a standard surgical method is not a time-consuming procedure.

However, there were controversial factors. First, the result was obtained in small groups and there was a chance of type I (alpha) error. The difference could be significant in a large group. Second, fluoroscopic image was not taken during anterior plating. The length of screws was measured before operation and fluoroscopic image was usually taken once to confirm operation level. If screws were inserted under fluoroscopic guidance, the operation time would be increased. Although malposition of screw or plate did not observed in the present study, fluoroscopic guidance may be necessary for multi-level instrumentation. This may increase operation time significantly. Moreover, additional bleeding of $15 \mathrm{ml}$ occurred during bone harvest and it may significantly increase with long-bone harvest for multi-level fusion. Therefore, for multi-level surgery, autologous bone harvest and anterior plating may be less time-efficient and more bleeding-prone procedure. Moreover, we did not considered short-term surgical morbidity such as donor site pain and dysphagia, because those were not the point of interest in the present study. Those are well known drawbacks of autologous bone harvest and anterior plating ${ }^{9,23}$. We should seriously consider those drawbacks in selecting surgical method.

\section{CONCLUSION}

ACDF with a standard method for single-level cervical disc disease was not a time-consuming procedure comparing standalone cage. When standard method seems to be beneficial in some cases, there may be no need to hesitate due to timeefficiency.

\section{REFERENCES}

1. Barsa P, Suchomel P: Factors affecting sagittal malalignment due to cage subsidence in standalone cage assisted anterior cervical fusion. Eur Spine J 16:1395-1400, 2007

2. Bartels RH, Donk RD, Feuth T: Subsidence of stand-alone cervical carbon fiber cages. Neurosurgery 58:502-508, 2006

3. Bridwell KH, Lenke LG, McEnery KW, Baldus C, Blanke K: Anterior fresh frozen structural allografts in the thoracic and lumbar spine. Do they work if combined with posterior fusion and instrumentation in adult patients with kyphosis or anterior column defects? Spine (Phila Pa 1976) 20:1410-1418, 1995.

4. Cho DY, Lee WY, Sheu PC: Treatment of multilevel cervical fusion with cages. Surg Neurol 62:378-386, 2004

5. Cloward RB: The anterior approach for removal of ruptured cervical disks. J Neurosurg 15:602-617, 1958

6. Demircan MN, Kutlay AM, Colak A, Kaya S, Tekin T, Kibici $\mathrm{K}$, et al: Multilevel cervical fusion without plates, screws or autogenous iliac crest bone graft. J Clin Neurosci 14:723-728, 2007

7. Dufour T, Huppert J, Louis C, Beaurain J, Stecken J, Aubourg $\mathrm{L}$, et al: Radiological analysis of 37 segments in cervical spine implanted with a peek stand-alone device, with at least one year follow-up. Br J Neurosurg 24:633-640, 2010

8. Fraser JF, Hartl R: Anterior approaches to fusion of the cervical spine: a metaanalysis of fusion rates. J Neurosurg Spine 6:298-303, 2007

9. Fujibayashi S, Neo M, Nakamura T: Stand-alone interbody cage versus anterior cervical plate for treatment of cervical disc herniation: sequential changes in cage subsidence. J Clin Neurosci 15:1017-1022, 2008

10. Gercek E, Arlet V, Delisle J, Marchesi D: Subsidence of standalone cervical cages in anterior interbody fusion: warning. Eur Spine J 12:513-516, 2003

11. Hakalo J, Pezowicz C, Wronski J, Bedzinski R, Kasprowicz M: Comparative biomechanical study of cervical spine stabilisation by cage alone, cage with plate, or plate-cage: a porcine model. J Orthop Surg (Hong Kong) 16:9-13, 2008

12. Joo YH, Lee JW, Kwon KY, Rhee JJ, Lee HK: Comparison of fusion with cage alone and plate instrumentation in two-level cervical degenerative disease. J Korean Neurosurg Soc 48: 342-346, 2010

13. Kast E, Derakhshani S, Bothmann M, Oberle J: Subsidence after anterior cervical inter-body fusion. A randomized prospective clinical trial. Neurosurg Rev 32:207-214, 2009

14. Katsuura A, Hukuda S, Saruhashi Y, Mori K: Kyphotic malalignment after anterior cervical fusion is one of the factors promoting the degenerative process in adjacent intervertebral levels. Eur Spine J 10:320-324, 2001

15. Kulkarni AG, Hee HT, Wong HK: Solis cage (PEEK) for anterior cervical fusion: preliminary radiological results with emphasis on fusion and subsidence. Spine J 7:205-209, 2007

16. Lin HL, Cho DY, Liu YF, Lee WY, Lee HC, Chen CC: Change of cervical balance following single to multi-level interbody fusion with cage. Br J Neurosurg 22:758-763, 2008

17. Nurick S: The pathogenesis of the spinal cord disorder associated with cervical spondylosis. Brain 95:87-100, 1972

18. Pechlivanis I, Thuring T, Brenke C, Seiz M, Thome C, Barth $\mathrm{M}$, et al: Non-fusion rates in anterior cervical discectomy and implantation of empty polyetheretherketone cages. Spine (Phila Pa 1976) 36:15-20, 2011

19. Ryu SI, Mitchell M, Kim DH: A prospective randomized study comparing a cervical carbon fiber cage to the Smith-Robinson technique with allograft and plating: up to 24 months followup. Eur Spine J 15:157-164, 2006

20. Schmieder K, Wolzik-Grossmann M, Pechlivanis I, Engelhardt M, Scholz M, Harders A: Subsidence of the wing titanium cage after anterior cervical interbody fusion: 2-year follow-up study. J Neurosurg Spine 4:447-453, 2006

21. Shad A, Leach JC, Teddy PJ, Cadoux-Hudson TA: Use of the Solis cage and local autologous bone graft for anterior cervical discectomy and fusion: early technical experience. J Neurosurg Spine 2:116-122, 2005

22. Song KJ, Lee KB: A preliminary study of the use of cage and 
plating for single-segment fusion in degenerative cervical spine disease. J Clin Neurosci 13:181-187, 2006

23. Summers BN, Eisenstein SM: Donor site pain from the ilium. A complication of lumbar spine fusion. J Bone Joint Surg Br 71:677-680, 1989

24. Sweet MG, Sweet JM, Jeremiah MP, Galazka SS: Diagnosis and treatment of osteoporosis. Am Fam Physician 79:193200, 2009

25. Thome C, Leheta O, Krauss JK, Zevgaridis D: A prospective randomized comparison of rectangular titanium cage fusion and iliac crest autograft fusion in patients undergoing anterior cervical discectomy. J Neurosurg Spine 4:1-9, 2006

26. Troyanovich SJ, Stroink AR, Kattner KA, Dornan WA, Gubina I: Does anterior plating maintain cervical lordosis versus conventional fusion techniques? A retrospective analysis of patients receiving single-level fusions. J Spinal Disord Tech 15: 69-74, 2002

27. van Jonbergen HP, Spruit M, Anderson PG, Pavlov PW: Anterior cervical interbody fusion with a titanium box cage: early radiological assessment of fusion and subsidence. Spine J 5:
645-649, 2005

28. Vavruch L, Hedlund R, Javid D, Leszniewski W, Shalabi A: A prospective randomized comparison between the cloward procedure and a carbon fiber cage in the cervical spine: a clinical and radiologic study. Spine (Phila Pa 1976) 27:1694-1701, 2002

29. Wang HS, Kim HY, Kim SW, Lee SM, Kim HS, Kim S-H: Advantages of the Plating for Anterior Cervical Discectomy and fusion: Comparison with Wearing Cervical Collar Without Plate. Korean J Spine 8:161-164, 2011

30. Wang X, Chen Y, Chen D, Yuan W, Chen X, Zhou X, et al: Anterior decompression and interbody fusion with BAK/C for cervical disc degenerative disorders. J Spinal Disord Tech 22: 240-245, 2009

31. Zhou J, Xia Q, Dong J, Li X, Zhou X, Fang T, et al: Comparison of stand-alone polyetheretherketone cages and iliac crest autografts for the treatment of cervical degenerative disc diseases. Acta Neurochir (Wien) 153:115-122, 2010

32. Zoega B, Karrholm J, Lind B: Outcome scores in degenerative cervical disc surgery. Eur Spine J 9:137-143, 2000 